\title{
Testimonio de la víctima y presunción de inocencia una mirada desde el ordenamiento español
}

\section{Testimony of the victim and presumption of innocence a look from the \\ Spanish legal system}

1 Pablo Ermely Espinosa Pico

https://orcid.org/0000-0002-8084-7628

Universidad Carlos III de Madrid

espinosapico@gmail.com

2 Byron Javier Chulco Lema

https://orcid.org/0000-0003-2584-9564

Universidad Intercultural de las Nacionalidades y Pueblos Indígenas Amawtay Wasi.

byron.chulco@uaw.edu.ec

3 Angelo Paul Vélez Brito

Instituto Superior Tecnológico España ISTE

angelo.velez@iste.edu.ec

4 Jorge Mauricio Salinas Arroba

Universidad Oberta de Catalunya

https://orcid.org/0000-0002-9070-9114

jsalinasar@uoc.edu.ec

Artículo de Investigación Científica y Tecnológica

Enviado: 09/11/2021

Revisado: $23 / 11 / 2021$

Aceptado: 21/12/2021

Publicado:05/02/2022

DOI: https://doi.org/10.33262/visionariodigital.v6i1.2068

Cítese: $\quad$ Espinosa Pico, P. E. E. P., Chulco Lema, B. J., Vélez Brito, A. P., \& Salinas Arroba, J. M. (2022). Testimonio de la víctima y presunción de inocencia una mirada desde el $\begin{array}{lllll}\text { ordenamiento } & \text { español. } & \text { Visionario } & \text { 6igital, }\end{array}$ https://doi.org/10.33262/visionariodigital.v6i1.2068

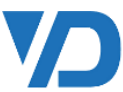

Ciencia Digital

VISIONARIO DIGITAL, es una Revista Científica, Trimestral, que se publicará en soporte electrónico tiene como misión contribuir a la formación de profesionales competentes con visión humanística y crítica que sean capaces de exponer sus resultados investigativos y científicos en la misma medida que se promueva mediante su intervención cambios positivos en la sociedad. https://visionariodigital.org

La revista es editada por la Editorial Ciencia Digital (Editorial de prestigio registrada en la Cámara Ecuatoriana de Libro con No de Afiliación 663) www.celibro.org.ec

Esta revista está protegida bajo una licencia Creative Commons AttributionNonCommercialNoDerivatives 4.0 International. Copia de la licencia: http://creativecommons.org/licenses/by-nc-nd/4.0/. 


Palabras
claves:
ordenamiento
español,
importancia
probatoria,
testimonio,
pruebas
testimoniales.

\section{Keywords:}

Spanish law, probative importance, testimony, testimonial evidence.

\section{Resumen}

Introducción. La importancia probatoria del testimonio ha sufrido una evolución desde el cálculo matemático de pruebas hasta las actuales reglas de valoración que exigen una motivación razonada. El testimonio único de la victima en delitos sexuales presenta problemáticas singulares que serán analizadas. Objetivo. Se busca el análisis de las pruebas testimoniales y sus garantías procesales, proponiendo cambios aplicando la perspectiva de género. Metodología. La metodología utilizada a se basa en un estudio del tema desde varias perspectivas como la históricalógica, deductiva, descriptiva, analítica, crítica y propositiva. Resultados. La doctrina jurisprudencial, ha ido incorporando determinados parámetros para analizar tanto al sujeto de la declaración, como el objeto de esta, desde la perspectiva de su credibilidad subjetiva, de su credibilidad objetiva y de la persistencia en la incriminación. Así como la exigencia de una mínima actividad probatoria y el desarrollo estándares de suficiencia probatoria, que establecen límites o imponen parámetros para determinar su validez Conclusión. Los parámetros y estándares probatorios han ayudado ha minimizar los errores en un proceso judicial. Sin embargo, aun es necesario herramientas como la perspectiva de género, que busca la integración del principio de igualdad en la interpretación y aplicación de las normas y eliminar la diferencia de oportunidades sociales, políticas y económicas de los individuos. La perspectiva de género debe utilizarse para erradicar prejuicios al momento de valorar una prueba testimonial o declaración.

\section{Abstract}

Introduction. The probative importance of the testimony has undergone an evolution from the mathematical calculation of evidence to the current evaluation rules that require reasoned motivation. The unique testimony of the victim in sexual crimes presents unique problems that will be analyzed. Objective: the analysis of the testimonial evidence and its procedural guarantees is sought, proposing changes applying the gender perspective. Methodology. The methodology used is based on a study of the subject from various perspectives such as historical-logical, deductive, descriptive, analytical, critical and propositional. Results. The jurisprudential doctrine has been incorporating certain 
parameters to analyze both the subject of the statement and its object, from the perspective of its subjective credibility, its objective credibility and the persistence of the incrimination. As well as the requirement of a minimum probative activity and the development of probative sufficiency standards, which establish limits or impose parameters to determine its validity. Conclusion. The parameters and evidentiary standards have helped to minimize the errors in a judicial process. However, tools such as the gender perspective are still necessary, which seek to integrate the principle of equality in the interpretation and application of norms and eliminate the difference in social, political and economic opportunities of individuals. The gender perspective must be used to eradicate prejudices when assessing testimonial evidence or statement.

\section{Introducción}

La validez probatoria del testimonio único como elemento de cargo suficiente para establecer una sentencia condenatoria, es producto de la evolución en las medidas de valoración probatoria. Partiendo del cálculo matemático que se hacía entre las pruebas positivas y negativas en el proceso de evaluación, se pasa de unas reglas de valoración en las que no se exigía un razonamiento motivador en la sentencia y se llega, con la introducción del principio de inocencia, a las actuales, que presentan como obligatorio una motivación razonada por parte de los jueces la valoración de las pruebas que desvirtúan o no la presunción de inocencia del acusado. Esto se ve reflejado en la declaración del testigo que afirma ser víctima directa del delito como única prueba de cargo, puesto que para que con este testimonio único se logre enervar la presunción de inocencia, se exigirá un análisis de la credibilidad de este. Que además de ayudar al juez a alcanzar una convicción subjetiva, le permita fundamentar objetivamente dicha motivación en el caso que no existan elementos externos de corroboración.

Este trabajo analizará el testimonio de la victima como única prueba de cargo en los delitos sexuales, los cuales al ser ilícitos que se producen generalmente en la intimidad y en el que el consentimiento es la clave para adjudicar o no responsabilidad, presentan una peculiar problemática a la hora de analizar y decidir sobre la credibilidad de este. Puesto que cuando la única prueba es el testimonio de la víctima frente a la del acusado, el juez deberá decidir sobre la fiabilidad de éstos aplicando una serie de estándares presentados por la doctrina jurisprudencial, a través de los cuales, podrá valorar si la credibilidad del testimonio de la víctima es suficiente para enervar la presunción de inocencia del acusado. 
Es en este proceso de valoración subjetiva, en el que se hace presente la victimización secundaria. Revictimización llevada a cabo por todas las partes del proceso, que, bajo la influencia de estereotipos, debate y valora el uso que la víctima debe darle a su cuerpo o cómo debe ser su reacción. Un ejemplo de esto lo encontramos en el mediático caso español de "La manada", en el que la víctima llegó a ser perseguida incluso por un detective privado contratado por la defensa, en el que encontramos un voto salvado que manifestaba que el magistrado solo observaba cinco varones y una mujer practicando "actos sexuales en un ambiente de jolgorio y regocijo". La perspectiva de género se hace necesaria.

Perspectiva de género planteada con el objetivo de cumplir efectivamente el derecho a la igualdad en el proceso, tanto el testimonio de la víctima como del acusado. Con ello evitar realizar una revictimización a la hora de analizar, mediante los parámetros jurisprudenciales, el testimonio de la víctima de los delitos de violencia sexual, sin caer en la falsa idea de que con esto se obtiene un fortalecimiento a la credibilidad de la víctima por el mismo hecho de serlo, desembocando esto, en una violación a la presunción de inocencia del acusado pues sería ahora este quién debe probar su inocencia. Se busca el análisis de los testimonios respetando sus garantías procesales. Es importante mencionar que, no solo debe plantearse la existencia de la perspectiva de género durante el proceso sino también en el contenido legislativo, el marco legal actual de los delitos sexuales parte de una de una herencia legislativa anticuada, por lo que primero es necesario analizar y adecuar la regulación de la perspectiva de género y con ello evitar el procedimiento revictimizador.

\section{Metodología}

La metodología utilizada a lo largo de la investigación se basa en un estudio del tema objeto de análisis desde varias perspectivas y metodologías como son, histórica-lógica, deductiva, descriptiva, analítica, crítica, propositiva y comparativa; sobre la jurisprudencia, normativa internacional, regional, nacional y doctrina referente al ámbito de estudio. Que incluye, además, el uso de técnicas como la cualitativa, estudio de caso, inducción analítica, comparación constante, análisis de contenido, análisis de eventos y análisis hermenéutico.

\section{Valoración del testimonio de la víctima como única prueba de cargo}

Históricamente la valoración probatoria del testimonio único ha sido regida por el criterio de "testis unus testis nulllus" (testigo único, testigo nulo). Incluso en épocas revolucionarias para el Derecho como es la ilustración, se defendía la insuficiencia probatoria de este testimonio. Pensadores como "Beccaria, Montesquieu o Filangieri se expresaron con toda claridad: (...) Siempre es necesario más de un testigo, porque en tanto que uno afirma y otro niega no hay nada cierto, y prevalece el derecho que cada cual 


\section{www.visionariodigital.org}

tiene a ser creído inocente" (Ramírez, 2018, p.10).

Esta postura fue cambiando a la par de la evolución de la valoración probatoria. De esta manera, se pasa de sentenciar siguiendo las reglas legales para la valoración probatoria que en síntesis resultaba ser un cálculo matemático entre pruebas positivas y pruebas negativas: "el testimonio de un testigo intachable, valía media prueba; el testimonio de un testigo sospechoso valía menos de media prueba; la declaración de un solo testigo carecía de valor probatorio" (Llera, 2014, p.2), a fallar basándose en la libre convicción. Se dota al juez de la libertad de apreciación a la hora de valorar las pruebas, se le pedía hacerlo siempre analizando objetivamente toda la actividad probatoria con la cautela de que este nunca ha presenciado el hecho personalmente y estará, por tanto, juzgando verdad de lo que informan las personas, sin embargo, esto no eximía de que se den arbitrariedades.

Ante todo, esto, es importante recordar las palabras de Grünwald (1993 citado en Frister, 2011), "el suceso histórico de un hecho punible nunca puede probarse con la firmeza propia de la lógica o las matemáticas y tampoco con la relativa seguridad que se conoce en las ciencias naturales" (p.2). De ahí que el sistema de pruebas antes descrito haya perdido importancia siendo esta pérdida, un punto de partida para la evolución que se ha llevado a cabo al respecto y que podemos ver reflejada en el artículo 741 de la Ley Criminal de Enjuiciamiento Española, la cual dota al juez de la libertad de apreciación.

De acuerdo con esta libre apreciación, en cuanto al testimonio de la víctima, "se decía que si el Tribunal, tras oír al testigo y al acusado, quedaba "íntimamente convencido" de la culpabilidad del segundo, por parecerle más creíble el primero, podía dar por acreditados los hechos objeto de acusación" (Ramírez, 2018, p.11). El testimonio de la víctima se considera entonces, prueba de cargo suficiente para dictar más allá de toda duda razonable, una sentencia condenatoria, incluidos los casos en los que éste fuese la única prueba de cargo.

Lo sostienen así, sentencias tanto del Tribunal Constitucional, SSTC 229/1991: “Como hemos manifestado reiteradamente (así en SSTC 201/1989 y 160/1990) en ausencia de otros testimonios, la declaración del perjudicado -en este caso, los Policías nacionales-, practicada normalmente en el juicio oral con las necesarias garantías procesales, tiene consideración de prueba testifical, y, como tal, puede constituir válida prueba de cargo, en lo que puede basarse la convicción del Juez para la determinación de los hechos del caso(...)"( SSTC 64/1994, de 28 de febrero). Como del Tribunal Supremo: "el testimonio de la víctima constituye en todo caso una prueba válida, que habrá de ser apreciada por el Tribunal, junto con los demás medios de prueba (...) (SSTS 788/2012 de 24 de octubre.). 
En ese mismo sentido el Tribunal ha declarado que: "La declaración de la víctima, según ha reconocido en numerosas ocasiones la jurisprudencia de este Tribunal Supremo y la del Tribunal Constitucional, puede ser considerada prueba de cargo suficiente para enervar la presunción de inocencia, incluso aunque fuese la única prueba disponible, lo que es frecuente que suceda en casos de delitos contra la libertad sexual, porque al producirse generalmente los hechos delictivos en un lugar oculto, se dificulta la concurrencia de otra prueba diferenciada. Así lo ha declarado tanto el Tribunal Constitucional (SSTC. 229/1991 de 28 de noviembre, 64/1994 de 28 de febrero y 195/2002, de 28 de octubre) como esta misma Sala (SSTS 339/2007, de 30 de abril, 187/2012, de 20 de marzo, núm. 688/2012, de 27 de septiembre, núm. 788/2012, de 24 de octubre, núm. 469/2013, de 5 de junio, etc.)" (STS 553/2014 de 30 de junio).

Es importante manifestar que en congruencia con el derecho a la presunción de inocencia "la exigencia de motivación no puede entenderse cumplida con una simple remisión a la prueba practicada. No basta con que se enumeren los elementos de prueba que han servido para alcanzar la convicción sobre la certeza de un hecho, sino que resulta imprescindible precisar sobre qué elementos se ha formado la convicción, las razones específicas en que se apoya la fiabilidad de cada medio de prueba y los motivos que permiten concretar el juicio de culpabilidad" (López, 2018). Es decir, que con la introducción del principio de presunción de inocencia, la jurisprudencia empieza a exigir a los jueces una motivación razonada de los elementos de convicción que enervarán o no el este principio, así mismo la prueba procesal dirigida a desvirtuarlo debe ser aquella practicada durante el juicio oral: en línea de principio sólo la prueba practicada en la audiencia del juicio oral asegura que la misma se ha practicado con respeto a las garantías fundamentales en la formación de la prueba, como son la contradicción, oralidad, inmediación, concentración y publicidad (STC 31/1981 \& STC 55/1982).

Esto se ve reflejado en la apreciación del testimonio único puesto que cuando la sentencia se base únicamente en el testimonio, debe exigirse una valoración más estricta que permita ir más allá de un convencimiento subjetivo, que haga que este testimonio sea objetivamente creíble. Atendiendo al derecho de la presunción de inocencia que exige la motivación en sentencia de que la culpabilidad del acusado se ha impuesto más allá de toda duda razonable se perfeccionan y limitan medios de prueba que puedan ser susceptibles de errores judiciales, este es el caso del testimonio único, el cual por no contar con elementos de corroboración es sujeto a parámetros de evaluación de fiabilidad que se han ido desarrollando jurisprudencialmente.

Ahora bien, de acuerdo con Frister (2011), “según la concepción hoy dominante parece presuponer dos cosas: del material probatorio incorporado en el juicio debe surgir -objetivamente una alta probabilidad de que el acusado sea culpable, y el juez tiene que haber alcanzado - personalmente, sobre la base de ese material probatorio, la certeza 


\section{www.visionariodigital.org}

acerca de la culpabilidad del acusado" (p.11).

Pero, ¿qué pasa en los casos que, por el carácter de intimidad o clandestinidad del ilícito, el único material probatorio es el testimonio de la víctima, cómo alcanzará el juez la certeza acerca de la personalidad? (Manzanero,1996). Como se ha manifestado anteriormente, la declaración de una sola persona puede ayudar al juez a alcanzar una convicción subjetiva, sin embargo, atendiendo a la lógica de que no se puede condenar o absolver a alguien fundados en una mera creencia subjetiva, la doctrina jurisprudencial ha desarrollado parámetros para dotar de objetividad probatoria al testimonio único. Éste al cumplir con todos o alguno de los criterios, alcanzará una credibilidad objetiva que permitirá al juez motivar con garantías de certeza y fiabilidad el quebrantamiento o no de la presunción de inocencia en la sentencia. Cumpliendo así tanto el requisito de objetividad como el de subjetividad.

\section{Parámetros jurisprudenciales del testimonio de la víctima}

La situación límite de riesgo para el derecho constitucional de presunción de inocencia se produce cuando la única prueba de cargo la constituye la declaración de la supuesta víctima del delito. En este sentido el Tribunal Supremo manifiesta:

"El riesgo se hace extremo si la supuesta víctima es precisamente quien inició el proceso, mediante la correspondiente denuncia o querella, haciéndose aún más acentuado si ejerce la acusación, pues en tal caso se constituye en única prueba de la acusación al propio acusador. Basta con formular la acusación y sostenerla personalmente en el juicio, para desplazar aparentemente la carga de la prueba sobre el acusado, obligándole a ser él quien demuestre su inocencia, frente a una prueba de cargo integrada únicamente por la palabra de quien le acusa. Todavía cabe alcanzar un supuesto más extremo, en aquellos casos en que la declaración del acusador no sólo es única prueba de la supuesta autoría del acusado sino también de la propia existencia del delito, del cual no existe acreditación alguna, fuera de las manifestaciones de quien efectúa la acusación; llegándose el grado máximo de indefensión para el acusado cuando la acusación fundada exclusivamente en la palabra del acusador es tan imprecisa en su circunstancia o en el tiempo que no hay prácticamente posibilidad alguna de prueba en contrario” (STS 1029/1997).

Como podemos ver, es justificable que la fiabilidad y credibilidad de los testimonios sea controlada con criterios objetivos, puesto que, el que recaiga sobre la víctima el lícito y la convierta en el sujeto pasivo, hace que pueda pesar sobre ella la sospecha de una posible falta de imparcialidad. Para controlar que esto no ocurra y que la declaración constituya una prueba fiable y objetivamente creíble con la que se pueda motivar una sentencia condenatoria, la doctrina jurisprudencial, ha ido incorporando determinados parámetros con los que se analizará tanto al sujeto de la declaración (que el testigo sea fiable) como 


\section{www.visionariodigital.org}

el objeto de la misma (que su declaración sea creíble) y se hará "desde la perspectiva de su credibilidad subjetiva, de su credibilidad objetiva y de la persistencia en la incriminación" (Aguilar, 2017, p.2).

Los parámetros los podemos encontrar en sentencias como la STS 1743/2018 que establece que:

"El viejo axioma testis unus testis nullus -se dice allí-fue erradicado del moderno proceso penal. Esa constatación, empero, no puede desembocar ni en la disminución del rigor con que debe examinarse la prueba, ni en una debilitación de la in dubio. La palabra de un solo testigo puede ser suficiente en abstracto para alcanzar la convicción subjetiva. Pero junto a ello la exigencia de una fundamentación objetivamente racional de la sentencia hace imposible fundar una condena sobre la base de la mera "creencia" en la palabra del testigo", a modo de un acto de fe ciego. Se hace imprescindible una valoración de la prueba especialmente profunda respecto de la credibilidad. Cuando una condena se basa en lo esencial en un testimonio ha de redoblarse el esfuerzo de motivación fáctica. Sus exigencias se acrecientan. Con ese marco enlaza bien el triple test-del que se hacen eco sentencia, recurso e impugnación del Fiscal- que se viene estableciendo por la jurisprudencia para valorar la credibilidad del testigo/víctima - persistencia en sus manifestaciones, elementos corroboradores, ausencia de motivos de incredibilidad ajenos a la propia acción delictiva-. No se trata de perfilar un presupuesto de validez o de utilizabilidad, sino de apuntar orientaciones para guiar la labor valorativa de ese tipo de prueba. Esas tres referencias, basadas en máximas de experiencia, ayudan a acertar en la decisión."

En cuanto a la ausencia de incredibilidad o credibilidad subjetivas de la víctima para que esta concurra, se debe verificar que las características físicas o psíquicas del testigo (edad, trastornos mentales, minusvalías) no afecten a la declaración y que no existan móviles espurios como odio, resentimientos, venganza o enemistad u otras razones (proteger a un tercero o cualquier otro) que ponga en duda la franqueza del testimonio. Es decir, se deben mostrar características tanto físicas como psíquicas para poder haber percibido lo que se relata.

Parece ser que con este parámetro se intenta más que analizar el testimonio en sí, analizar a la persona que declara, su relación con acusado, los comportamientos que se esperan de ella. Es muy válido argumentar que este proceso es necesario porque no se puede sustentar un fallo condenatorio en la mera creencia subjetiva del magistrado, y que para llegar a una certeza personal deba estudiar lo antes mencionado, sin embargo, también es válido manifestar que en este momento es uno de los tantos que son susceptibles de provocar una victimización secundaria al sujeto pasivo. Tanto defensa como acusación defenderán 
un planteamiento en el que la vida, relaciones y comportamientos de la víctima y el agresor serán el centro de atención, y esto se debatirá desde un enfoque en mayoría estereotipado con un discurso conservador. Así mismo el magistrado, al momento de juzgar bajo las máximas de la experiencia, proyectará la vivencia y experiencia propia que lamentablemente aún sigue conteniendo sesgos de desigualdad y tradiciones retrogradas. Un gran ejemplo de esto lo encontramos en el caso "La Manada" en el que la defensa contrató un detective privado para analizar los comportamientos de la víctima.

Se puede decir por tanto que, para analizar el testimonio de la víctima como prueba de cargo, se parte de juzgar su persona, lo que la convierte parcialmente en acusada. Es importante, entonces, que en este momento en el que se cuestiona cuál es el comportamiento y la reacción que ambos deben tener frente al delito, se haga eliminando todo sesgo o estereotipo. "El juez puede, y obviamente también debe, esforzarse tanto como sea posible por excluir los factores externos, reflexionando sobre los fundamentos de su juicio" (Frister, 2011, p.17).

Por su parte el parámetro de persistencia de la incriminación se traduce en que el relato no debe presentar ambigüedades y ser el mismo a lo largo de todo el proceso (en instrucción, sedes policiales, en el juicio oral, etc.). Además, debe ser clara sin contradicciones, ambigüedades, ni presentar cambios significativos en la narración.

Y finalmente, el parámetro de verosimilitud del testimonio exige dos cuestiones: que la declaración sea lógica y coherente y que esté rodeada de corroboraciones externas de carácter objetivo. Que la valoración se sustente con algo más que la pura manifestación subjetiva de la víctima, apoyando el testimonio, por ejemplo, con peritajes médicos o forenses que determinen los resultados del ilícito. Pero, ¿qué ocurre cuando por consecuencias intrínsecas al delito no se puede contar con los elementos corroboradores, cuando el único elemento probatorio es el relato subjetivo de la víctima?, ¿deja el testimonio único de ser prueba de cargo suficiente para enervar la presunción de inocencia y por ende dejamos el delito en la impunidad, porque no pudimos comprobar con elementos periféricos su relato? La jurisprudencia ante esto dice que no son requisitos imprescindibles, la ausencia de uno no desvirtuará por completo la credibilidad del testimonio, tampoco la concurrencia de todos garantizará la fiabilidad del mismo como prueba suficiente:

"Son puntos de contraste que no se pueden soslayar. Pero eso no significa que cuando se cubran las tres condiciones haya que otorgar "por imperativo legal" crédito al testimonio. $\mathrm{Ni}$, tampoco, en la otra cara, que cuando falte una o varias, la prueba ya no pueda ser valorada y, ex lege, por ministerio de la ley - o de la doctrina legal en este caso-, se considere insuficiente para fundar una condena" (STS 1743/2018). 
"En supuestos como el que se examina, de relaciones producidas entre dos personas en un contexto intimo, existe cierta tendencia a postular para la declaración de la que aparece procesalmente como víctima un plus de credibilidad. Es decir, la aplicación de un estándar de prueba menos exigente. Pero sucede que el derecho a la presunción de inocencia es de carácter absoluto, lo que significa que, cualquiera que sea la imputación, debe estar bien acreditada en todos sus elementos centrales, para que resulte justificada una sentencia condenatoria." (STS 490/2010).

Estas conclusiones jurisprudenciales se deben a la idea de que "al igual que el imputado tiene derecho a que se parta de su inocencia, la víctima tiene necesidad de ser creída, el derecho a que su testimonio no sea minusvalorado realizando apreciaciones superficiales que distorsionen la realidad de su relato" (López, 2018, p.4).

A pesar de cómo manifiesta Frister (2011):

toda formación de convicción sobre hechos no observados por uno mismo se encuentra también caracterizada por percepciones y experiencias del juzgador no expresables en palabras, no existe —en la medida en que no se quiera regresar a las reglas probatorias rígidas del proceso inquisitorio - un juicio objetivo sobre el resultado de las pruebas colectadas. Entonces, el dictado de una condena no puede depender ni por sí solo, ni junto con el requisito de la certeza personal, de un resultado probatorio - objetivo, es decir, que sea conceptualmente controlable por completo. (p.16)

Los criterios antes expuestos, intentarán ayudar al magistrado a alcanzar una convicción objetiva la cual, sumada a la certeza personal o convicción subjetiva, servirán de fundamentos para llevar a cabo el procedimiento de valoración de la prueba el quebrantamiento o no quebrantamiento de la presunción de inocencia del acusado en la sentencia.

\section{Presunción de inocencia frente al testimonio de la victima}

El derecho a la presunción de inocencia fue incorporado en 1879 en la Declaración de Derechos del Hombre y del Ciudadano, en su artículo 9 rezaba que se presumirá la inocencia de todo hombre hasta que no sea declarado culpable. El contenido del derecho se presenta como un límite al poder punitivo estatal con el fin de evitar la arbitrariedad del poder del monarca absoluto. Se desarrolla en el derecho sustantivo el principio de legalidad y en el procesal la presunción de inocencia.

Esto fue resultado de que los motivos de preocupación en la ilustración fueron tanto la presunción de inocencia como humanización del sistema penal. Terminar con el sistema inquisitorio que se venía dando e incorporar un sistema acusatorio, en el que el juez 
imparcial, respete el estatuto jurídico del imputado. Dado que el proceso penal en una sociedad democrática cumple un doble fin: castigar al culpable y exigirle responsabilidad, y ser un mecanismo efectivo para proteger a las personas inocentes y evitar el error, la presunción de inocencia cumple una función limitadora como garantía de verdad y libertad: el proceso está concebido para dar protección al inocente, por eso es una garantía de libertad y para evitar el error por eso es una garantía de verdad.

En España este derecho esta recogido en el art. 24.2 de la Constitución: “Asimismo, todos tienen derecho al Juez ordinario predeterminado por la ley, a la defensa y a la asistencia de letrado, a ser informados de la acusación formulada contra ellos, a un proceso público sin dilaciones indebidas y con todas las garantías, a utilizar los medios de prueba pertinentes para su defensa, a no declarar contra sí mismos, a no confesarse culpables y a la presunción de inocencia." Se constituye, así como una garantía constitucional en el proceso penal.

Para garantizar esta tutela el legislador se ve en la obligación de estructurar una nueva forma de proceso para salvaguardar, creando crea un modelo procesal en el que la tutela de los inocentes ocupe un lugar importante, en el que el error esté minimizado absolutamente y en el que se pusiese márgenes de calidad para evitar errores, reducirlo al mínimo. El cauce en anclaje normativo, de esto es la presunción de inocencia, para esto hay que objetivar el proceso de valoración de la prueba. Creando estándares para valorarla y exigiendo la motivación a los jueces.

En España se ha producido una situación peculiar en lo que respecta a este derecho, puesto que mientras en el resto de Europa, la garantía en la que gira un proceso regido por el principio de legalidad será el derecho a un proceso justo, en España será el derecho a la presunción de inocencia. Los puntos transversales de este derecho se manifiestan jurisprudencialmente en las sentencias del Tribunal Constitucional, la incorporación de la exigencia de una mínima actividad probatoria, practicada en el juicio oral respetando las garantías fundamentales en la formación de la prueba (contradicción, oralidad, inmediación y publicidad); la certeza de culpabilidad en la STC 55/1982, para condenar hace falta la certeza de la culpabilidad obtenida de la valoración de la prueba. "Así, el principio "in dubio pro reo" dejaba de ser una simple regla moral de prudencia dirigida al juzgador, de quien se esperaba cierta magnanimidad, y se convertía no sólo en un derecho fundamental directamente exigible sino en el principio estructural del sistema procesal" (Ramírez, 2018, p.12). Posteriormente se fueron desarrollando estándares de suficiencia de la para determinadas pruebas, que establecían límites o imponían parámetros para determinar su validez. En el testimonio de la víctima, concretamente, se exigen elementos corroboradores periféricos con los que sustentar la declaración, se puede determinar con esto que, la convicción subjetiva no será suficiente para sustentar una condena. 
Ambas exigencias son expresión de un ideal de racionalidad que no sólo se configura como un presupuesto de legitimidad, sino también de validez de la condena y del juicio. "La condena presupone el conocimiento racional de los hechos, al que sólo se puede acceder a través de la conexión lógica entre los hechos y las pruebas que constituyen los fundamentos de la convicción del juez, cuya interpretación no sólo ha de realizarse según criterios de racionalidad, sino que además ha de expresarse en la sentencia, exteriorizando la valoración probatoria, es decir, el motivo de las conclusiones a las que el tribunal ha llegado aplicando las reglas del conocimiento humano y de la experiencia” (López, 2003, p.3).

Ahora bien, ¿qué sucede con este derecho a la presunción de inocencia en los casos en los que la única prueba de cargo es el testimonio de la víctima?, ¿la palabra del testigo, sin ningún elemento corroborador externo, objetivo, periférico es suficiente para ayudar al magistrado a alcanzar la convicción subjetiva y fundamentar objetiva y racionalmente la sentencia, basado en la certeza personal? La jurisprudencia responde a esta duda manifestando que: "Cuando una condena se basa en lo esencial en un testimonio ha de redoblarse el esfuerzo de motivación fáctica. Sus exigencias se acrecientan” (STS 1743/2018).

Así mismo, en la STS 2182/2018, de 13 de junio el ponente Sr. Magro Servet (citado en Ramírez, 2018), sostiene que la "víctima" es un testigo privilegiado o cualificado en la medida en que ha sufrido y presenciado el hecho:

En estos casos, la víctima se encuentra procesalmente en la situación de testigo, pero a diferencia del resto de testigos, es víctima y ello debería tener un cierto reflejo diferenciador desde el punto de vista de los medios de prueba, ya que la introducción de la posición de la víctima en la categoría de mero testigo desnaturaliza la verdadera posición(...), Y esto es relevante cuando estamos tratando de la declaración de la víctima en el proceso penal, y, sobre todo, en casos de crímenes de género en los que las víctimas se enfrentan a un episodio realmente dramático, cual es comprobar que su pareja, o ex pareja, como aquí ocurre, toma la decisión de acabar con su vida, por lo que la versión que puede ofrecer del episodio vivido es de gran relevancia, pero no como mero testigo visual, sino como un testigo privilegiado, cuya declaración es valorada por el Tribunal bajo los principios ya expuestos en orden a apreciar su credibilidad, persistencia (...). (p.19)

Es decir, el testimonio de la víctima contaría con un plus de credibilidad por la situación en la que esta se encuentra, esto no quita que el mismo deba ser efectivamente evaluado bajo los parámetros antes mencionados, pero como se mencionó también no es necesario que se de la concurrencia de todos para que el relato se convierta en objetivamente creíble, dotando a la convicción subjetiva del juez de suficiencia para motivar la enervación o no 
enervación de la presunción de inocencia. Además, atendiendo a lo anterior se podría determinar que entre el conflicto entre la libre convicción subjetiva y la fundamentación objetivo racionalista a la hora de fundamentar una sentencia, la certeza personal tiene gran importancia y puede superponerse a lo otro.

Esto se debe a como afirma Frister (2011):

dado que toda formación de convicción sobre hechos no observados por uno mismo se encuentra también caracterizada por percepciones y experiencias del juzgador no expresables en palabras, no existe — en la medida en que no se quiera regresar a las reglas probatorias rígidas del proceso inquisitorio- un juicio objetivo sobre el resultado de las pruebas colectadas. Entonces, el dictado de una condena no puede depender ni por sí solo, ni junto con el requisito de la certeza personal, de un resultado probatorio - objetivo, es decir, que sea conceptualmente controlable por completo. (p.16)

Pero, es compatible esta afirmación de que dar estatus de víctima al sujeto pasivo denunciante, ¿sin una sentencia prueba con la presunción de inocencia? ¿se estaría pasando de una presunción de inocencia a una presunción de culpabilidad?

De todo lo manifestado anteriormente podemos concluir las siguientes premisas: la presunción de inocencia del acusado debe presumirse hasta que no haya sido desvirtuada, que sólo las pruebas practicadas en juicio oral con respeto a las garantías constitucionales podrán hacerlo, que el juzgador deberá motivar de manera suficiente su fallo y que, gracias al sistema acusatorio, el acusado no tiene que probar su inocencia. Como se dijo anteriormente, la presunción de inocencia nace de la preocupación iusnaturalista de humanizar el proceso, con la intención de nivelar, en cierta medida, la desigualdad de las partes. Sin embargo, es bien sabido que en los delitos sexuales, la posición víctimaacusado no es igualitaria, siendo la víctima la peor posicionada : el marco jurídico que regula el delito parte de tratar al ilícito con un carácter paternalista (hace unos años las leyes protegían "el honor de la mujer" y no su libertad sexual), durante el procedimiento, con el fin de constatar la veracidad y credibilidad de su testimonio, a la víctima se le hará un análisis exhaustivo de su vida, sus relaciones y sus comportamiento, pero esto no se hará, como nos gustaría a todos, desde un enfoque igualitario en el que no se prejuzgue a la víctima, todo lo contrarío se hará partiendo de la concepción estereotipada que lamentablemente aun se da en la sociedad. Por lo que no resulta exagerado plantear que en estos delitos la parte débil del conflicto, la que merece mayor protección, es la víctima y no tanto el acusado (Gatti, 2016).

Respecto a la posible inversión de la carga de la prueba en la que en lugar de una presunción de inocencia se da una presunción de culpabilidad, cabe preguntarse porqué resulta tan descabellada la idea, si el ordenamiento jurídico la tiene prevista para otras 


\section{www.visionariodigital.org}

excepciones como son, por ejemplo:

Supuestos derivados de la Ley Mordaza (el testimonio de los agentes es considerado prueba suficiente y es el acusado quien debe demostrar que dicho testimonio es falso). Competencia desleal y publicidad ilícita (las empresas deben demostrar que no engañaban a los potenciales clientes). Alegaciones sobre actuaciones discriminatorias (el bar debe demostrar que no discriminó al cliente por su raza u orientación sexual). Responsabilidad civil y seguro en la circulación de vehículos a motor (si atropellas a un peatón debes demostrar que fue él el que provocó la negligencia). Daños y perjuicios causados a los consumidores y usuarios (las empresas deben probar que el mal uso del aparato fue por parte del consumidor). Y otros tantos asuntos sobre disputas laborales, patentes, pólizas o ataques al derecho al honor o la intimidad (Trula, 2018).

¿Porqué no plantearse esta excepción también en los delitos sexuales, en los que como hemos visto y veremos en el capítulo siguiente, la víctima es revictimizada por la ley, el proceso, y la sociedad, lo que la deja en un estado de indefensión y desigualdad? ¿por qué no garantizarle una justicia efectiva que parta desde la igualdad y evite la impunidad de los acusados por no contar con "suficiencia probatoria?

\section{Perspectiva de género}

"Podríamos consensuar entender por perspectiva de género la reivindicación que parte de comprender que la realidad no se puede analizar de forma aparentemente neutra sin que esa neutralidad, en situaciones de desigualdad, derive en perpetuar y consolidar la desigualdad" (Varela \& Fernández, 2018, p. 3).

La perspectiva de género es un planteamiento de obligación legal recogido tanto en instrumentos internacionales como en la legislación nacional; en el ámbito internacional, encontramos al artículo 5 del CEDAW que determina que "los Estados deben tomar todas las medidas apropiadas para modificar los patrones socioculturales de conducta de hombres y mujeres, con miras a alcanzar la eliminación de los prejuicios y las prácticas consuetudinarias y de cualquier otra índole que estén basados en la idea de la inferioridad o superioridad de cualquiera de los sexos o en funciones estereotipadas de hombres y mujeres", su artículo 15.2 se hace referencia a la igualdad entre hombres y mujeres en todas las etapas del procedimiento judicial. Así mismo el Convenio del Consejo de Europa, en capítulo IV, sobre la Investigación, procedimientos, derecho procesal y medidas de protección disponer que "Las Partes adoptarán las medidas legislativas o de otro tipo necesarias, de conformidad con los principios fundamentales de los derechos humanos y teniendo en cuenta la perspectiva de género en este tipo de violencia, para garantizar una investigación y un procedimiento efectivos por los delitos previstos en el presente Convenio". 


\section{www.visionariodigital.org}

En el ámbito español este planteamiento se normativiza en la Ley Orgánica 3/2007 de 22 de marzo, para la igualdad efectiva de mujeres y hombres, la cual en su art. 4 dispone " $l a$ integración del principio de igualdad en la interpretación y aplicación de las normas. La igualdad de trato y de oportunidades entre mujeres y hombres es un principio informador del ordenamiento jurídico y, como tal, se integrará y observará en la interpretación y aplicación de las normas jurídicas".

A pesar de que ya es un imperativo legal, la perspectiva de género, pasa desapercibida en los delitos sexuales, "a pesar de que, precisamente, es una de las manifestaciones más claras del ejercicio del poder de sojuzgamiento del hombre sobre la mujer. Y es que en estos delitos se produce una de las exhibiciones más claras de la dominación masculina: la que conduce a la cosificación sexual de la mujer. En la cultura de la violación, el hombre, alcanzado la voluntad de la mujer mediante el uso de la violencia o anulando la voluntad de la misma acudiendo a sustancias o fármacos que le conducen a la inconsciencia. En una cultura de abuso de poder masculina que se asienta en el principio de desigualdad" (STS 32/2015 de tres de febrero).

Es por esto importante manifestar que, como mantiene la magistrada Yolanda Rueda (219):

hay que identificar además la clase de estereotipo; así, si se trata de un estereotipo de sexo (referido a las capacidades físicas o cognitivas de las mujeres y por tanto las diferencias físicas y biológicas entre hombres y mujeres y en las nociones generalizadas o preconcepciones que conciernen a dichos atributos físicos o biológicos), de un estereotipo sobre los roles sexuales (aluden a los roles y comportamientos que se atribuyen a, y se esperan de, los hombres y las mujeres en base a sus construcciones físicas, sociales y culturales, lo que las mujeres deberían ser) o compuesto (cuando el género interseca con otros factores como la edad, raza, religión. Por ejemplo, los estereotipos basados en el género y la edad pueden unirse para producir estereotipos específicos relacionados con las adolescentes, las mujeres en edad reproductiva o de la tercera edad. (p.37).

Y es necesario hacerlo puesto que estos se presentan a lo largo del todo proceso penal, desde la misma redacción de la ley hasta el momento del juzgamiento.

Una vez identificados, se podrá introducir la perspectiva de género tanto en la ley, en el proceso y el juzgamiento.

La perspectiva de género se hace necesaria a la hora de la redacción normativa, por ejemplo, para alcanzar una igualdad real que supere el carácter neutral y por esa razón posteriormente sesgado. No cabe duda de que se han dado importantes evoluciones dentro de los marcos jurídicos y legislativos al respecto. A lo largo de la historia, se deja de velar 
por la "honestidad" de la mujer como proyección moral de la costumbre social, pasando de proteger un doble bien jurídico que velaba por los derechos de la mujer agredida y el de la dignidad de su familia, en los siglos XIX y XX, al doble bien jurídico que defiende ahora, el de la mujer ofendida y el de su género, sin embargo aún hay cambios necesarios por hacer, uno de ellos por ejemplo, es el dejar de incluir el término consentimiento dentro de los tipos penales de delitos sexuales, partir de que efectivamente no se consintió el acto y, con ello evitarle una revictimización a lo largo del proceso (Ventura \& Iglesias, 2020).

Durante el desarrollo del proceso, se precisa, sobre todo, al momento de analizar el testimonio de la víctima, "su operatividad, sobre todo, debe situarse evitando utilizar estereotipos para evaluar el crédito que merecen los testimonios de las mujeres víctimas de los delitos de violencia sexual". Esta operatividad debe centrarse también, en la utilización de medios de comprobación más respetuosos con la personalidad de la víctima (López, 2018, p.8). La perspectiva de género, por tanto, exigirá que "el relato que realiza la mujer que narra haber sido víctima de actos violentos protagonizados por el hombre se evalúe eliminando estereotipos que tratan de universalizar como criterios de racionalidad simples máximas de experiencia machistas (v.gr: el estereotipo de "víctima ideal" que, tras sufrir el hecho, lo denuncia inmediatamente, mantiene siempre un relato idéntico de lo acontecido y se aísla socialmente; el estereotipo de mujer sexualmente disponible para cualquier hombre, inducido de datos con pretendido valor indiciario tales como su vestimenta, su estado de embriaguez o el lugar y hora de la noche en la que se le encuentra, y, frente a él, el de la mujer decente, o los de la buena esposa o buena madre)" (Ramírez, 2018, p.17).

Finalmente, a la hora de juzgar, es imperante la necesidad de promover la incorporación transversal la perspectiva de género en las decisiones judiciales y con ello evitar encontrarnos con sentencias basadas en modelos estereotipados de comportamientos que “deben" tener las mujeres frente a los escenarios que se presentan (Buen, 2018). En 2016 la Audiencia Provincial de Murcia no consideró culpable de abuso y acoso sexual a un jefe que llamaba "chochitos" y dejaba notas como "este año si es posible estés más buena" a sus empleadas, sino que lo consideró como una falta de consideración y desatención del jefe; en 2017 la Audiencia Provincial de Cantabria consideró abuso sexual y no agresión la de un hombre hacia una niña de cinco años porque no se probó que la menor opusiera resistencia física o protestara, llorara o gritara; en 2018 la Audiencia Provincial de Navarra condena por abuso y no por agresión a cinco hombres que abusaron sexualmente de una mujer de 18 años durante las fiestas de San Fermín, considerando que no existió violencia ni intimidación. Que los operadores de justicias valoren las diferentes condiciones, situaciones y necesidades de mujeres y hombres evitando que estas se conviertan en desigualdades que desemboquen en relaciones asimétricas.

\section{Conclusiones}


- Es necesario capacitar a los operadores de justicia en esta materia con el fin de lograr una sociedad respetuosa de la dignidad humana. Como se ha manifestado anteriormente, lamentablemente en la sociedad aun existen prejuicios de género, el Sistema Judicial no es ajeno a esto y, por ende, tampoco lo es de sus creencias estereotipadas: se legisla, sentencia y litiga conforme a los cánones, la forma de vida y la educación de la sociedad. De ahí que se necesite un cambio que nos dirija de esa sociedad en la que impera una igualdad formal, hacía una en la que se evolucione hacia una igualdad real, efectiva. Puesto que, por ejemplo, cuando la única prueba es el testimonio de la víctima frente a la del acusado, el juez deberá decidir sobre la fiabilidad de éstos aplicando una serie de estándares presentados por la doctrina jurisprudencial, a través de los cuales, podrá valorar si la credibilidad del testimonio de la víctima es suficiente para enervar la presunción de inocencia del acusado. Es en este proceso de valoración subjetiva, en el que se hace presente la victimización secundaria. Revictimización llevada a cabo por todas las partes proceso, que bajo el ideal estereotipado patriarcal se debate y valora el uso que la víctima debe darle a su cuerpo o cómo debe ser su reacción

- La perspectiva de género debe ser entendida, por tanto, como una técnica jurídica aplicada a todas las fases del proceso (valoración de pruebas e interpretación de la norma) que considera los efectos discriminatorios de los estereotipos de género dentro del litigio, analiza que puedan estar generando una diferencia de oportunidades o derechos (relación asimétrica) y en caso de que esto suceda, los erradica de la aplicación o interpretación de la norma, compensando así el desequilibrio que haya podido ocasionar, la perspectiva de género busca la integración del principio de igualdad en la interpretación y aplicación de las normas y eliminar la diferencia de oportunidades sociales, políticas y económicas de las que gozan hombres y mujeres.

- Ahora bien, la utilidad de la perspectiva de género en la valoración de el testimonio de la víctima debería servir para eliminar los estereotipos discriminatorios. Especialmente en delitos sexuales en que muchas veces se juzga el testimonio de la víctima junto a su pasado, forma de vestir, estado civil, consumo de alcohol, etc. Así como en delitos, que, por su naturaleza de ocultos, el testimonio de la víctima sobrevive como prueba única. Estos estereotipos discriminatorios afectan las máximas de la experiencia y la sana crítica del Juez, que si bien es un profesional del derecho también es una persona que se formo rodeado de estos prejuicios que afectan a la sociedad en general. Por lo que es necesario reformularlas con la utilización de la perspectiva de género como filtro modulador, especialmente de las máximas de experiencia que no tienen fundamento científico si no mas bien empírico, mas aún con falsas máximas de experiencia que no tienen fundamento alguno y pasan a ser simples prejuicios sociales. 


\section{www.visionariodigital.org}

- La perspectiva de género debe utilizarse para erradicar estos prejuicios al momento de valorar una prueba testimonial o declaración. Así la verdadera función de la perspectiva de género al analizar prueba testimonial se daría eliminando prejuicios y estereotipos al momento de valorar la prueba, sin vulnerar principios como la presunción de inocencia.

\section{Referencias Bibliográficas}

Aguilar Gualda, S. D. (2017). El testigo único o singular (A propósito de la sentencia condenatoria en materia penal). Marcial Pons.

Buen Unna, C. E. (2018). El derecho desde una perspectiva de género. Tirant lo Blanch.

Frister, H. (2011). La certeza personal como presupuesto de la condena en el proceso penal. Revista para el Análisis del Derecho. (n.3), pp. 2-26. https://raco.cat/index.php/InDret/article/view/366194

Gatti, G. (2016). Tiene [la] palabra la víctima pura [?]. El vacío social, el testimonio y la desesperación del investigador ante el sufrimiento sin forma ni lenguaje. Kamchatka.

Llera, C. E. (2014). El testigo único o singular (A propósito de la sentencia condenatoria en materia penal). Institutas. Revista de Derecho Procesal. Pp,1-11.

López Ortega, J.J. (2018). Breves Reflexiones Yo Sí Te Creo. Boletín Comisión Penal Perspectiva de Género en el Proceso Penal, 2 (10), pp. 2-8.

López Ortega, J.J. (2003). Hecho material, hecho psíquico y juicio de valor en el veredicto del Tribunal del Jurado. Estudios de Derecho Judicial, 45 (2003), pp. 1-11.

Manzanero, A.L. (1996). Evaluando el testimonio de menores testigos y víctimas de abuso sexual: An evaluation of the evidence of child witness and victim of sexual abuse. Colegio Oficial de Psicólogos de Madrid.

Ramírez Ortiz, J.L. (2018). El testimonio único de quien afirma ser víctima desde la perspectiva de género. Boletín Comisión Penal Perspectiva de Género en el Proceso Penal, 2 (10), pp. 9-23.

Rueda Soriano, Y. (2018). Los Estereotipos de Género en el Proceso Penal. Boletín. Comisión Penal Perspectiva de Género en el Proceso Penal, 1 (10), pp. 12-20.

Sentencia del Tribunal Constitucional (SSTC). (1994). SSTC 64/1994, de 28 de febrero. 


\section{www.visionariodigital.org}

Sentencia del Tribunal Constitucional (SSTC). (1991). SSTC 229/1991 de 28 de noviembre.

Sentencia del Tribunal Constitucional (SSTC). (2002). SSTC. 195/2002, de 28 de octubre.

Sentencia del Tribunal Constitucional (STC). (1981). STC 31/1981

Sentencia del Tribunal Constitucional (STC). (1982). STC 55/1982.

Sentencia del Tribunal Constitucional (SSTC). (1989). SSTC 201/1989

Sentencia del Tribunal Constitucional (SSTC). (1990). SSTC 160/1990

Sentencia del Tribunal Supremo (SSTS). (2012). SSTS 788/2012 de 24 de octubre.

Sentencia del Tribunal Supremo (STS). (2014). STS 553/2014 de 30 de junio.

Sentencia del Tribunal Supremo (STS). (2018). STS 2182/2018, de 13 de junio

Sentencia del Tribunal Supremo (STS). (1997). STS 1029/1997, de 29 de diciembre.

Sentencia del Tribunal Supremo (STS). (2018). STS 1743/2018 del 8 de mayo.

Sentencia del Tribunal Supremo (STS). (2010). STS 490/2010 de 21 de mayo.

Sentencia del Tribunal Supremo (SSTS). (2007). SSTS 339/2007 de 30 de abril.

Sentencia del Tribunal Supremo (SSTS). (2012). SSTS 187/2012, de 20 de marzo

Sentencia del Tribunal Supremo (SSTS). (2012). SSTS 688/2012, de 27 de septiembre

Sentencia del Tribunal Supremo (SSTS). (2013). SSTS 469/2013, de 5 de junio

Trula, M. (2018). Por qué el \#MeToo comienza a cuestionar la presunción de inocencia en casos de violencia machista. Recuperado de https://magnet.xataka.com/endiez-minutos/que-metoo-comienza-a-cuestionar-presuncion-inocencia-casosviolencia- machista

Varela Castellón, X. \& Fernández Suárez, N. (2018). Algunas Reflexiones Sobre la Perspectiva de Género. Boletín Comisión Penal Perspectiva de Género en el Proceso Penal, 1 (10), pp. 7-11

Ventura Franch, A. \& Iglesias Barez, M. (2020). Manual de derecho constitucional español con perspectiva de género. Ediciones Universidad de Salamanca. 


\section{VP Digital}

El artículo que se publica es de exclusiva responsabilidad de los autores y no necesariamente reflejan el pensamiento de la Revista Visionario Digital.

\section{¿Ciencia}

El artículo queda en propiedad de la revista y, por tanto, su publicación parcial y/o total en otro medio tiene que ser autorizado por el director de la Revista Visionario Digital.
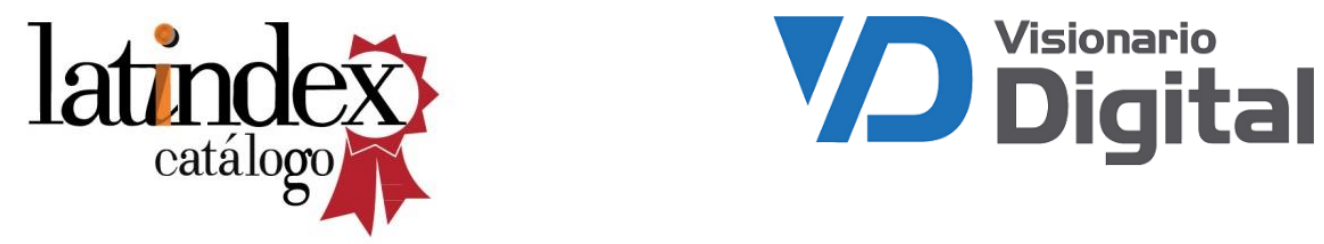

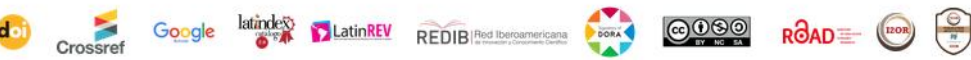

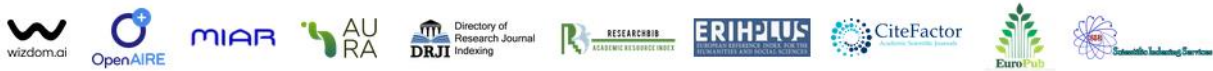

